\title{
The pharmacovigilance of psychoactive medications in Brazil
}

\section{A farmacovigilância dos medicamentos psicoativos no Brasil}

\author{
Elisaldo Luiz de Araújo Carlini and Solange Aparecida Nappo \\ CEBRID - Brazilian Information Center on Psychotropic Drugs. Medical Course of Sociology on Drug Abuse. Department of Psychobiology. Paulista \\ Medical School. Federal University of São Paulo. São Paulo, SP, Brazil
}

\begin{abstract}
Objective: The present study aimed to analyze 219 notifications of suspected adverse reactions (AR) produced by psychoactive medicaments (ARPM), notified by Brazilian psychiatrists, during a 3-month period (April 1999 up to September 2001).

Method: A notifying card for adverse reactions possibly produced by psychoactive medications was quarterly sent to all psychiatrists affiliated to the Brazilian Association of Psychiatry. Once each notification, dully filled in, was received, the possible adverse reaction was analyzed in order to verify the causality

Results: The psychiatrists classified as severe 50 of the ARPMs; 150 others were not considered as severe. Among the severe ones there were 3 deaths, 12 life-threatening reactions, 26 ARPMs required or prolonged hospitalization and 9 notifications described temporary disability of the patients. Among the medications, antidepressants ranked first with 122 ARPMs being notified, followed by neuroleptics (46 ARPMs) and antiepiletic medicaments (25 ARPMs). The three main organs and systems affected by the ARs were the Central Nervous System with 102 ARs, skin and mucosa with 44 and gastrointestinal with 21 ARPMs.

Conclusion: Considering causality, i.e., the association between the medication and the described AR, 24 cases were considered as Definite (with positive dechallenge and rechallenge, i.e., withdrawal and reintroduction of the medication) and 134 other ARPMs were classified as Probable (only dechallenge positive; only with medication withdrawal; rechallenge was not performed).
\end{abstract}

Keywords Adverse reaction to medicines. Pharmacovigilance. Psychoactive medicaments. Causality of adverse drug reactions.

Resumo Objetivo: O presente estudo visou analisar 219 notificações de suspeita de reações adversas (RA) produzidas por medicamentos psicoativos (RAMPs), preenchidas por médicos psiquiatras durante um período de três meses (abril de 1995 a setembro de 2001).

Método: Uma ficha para notificação de reações adversas possivelmente produzidas por medicamentos psicoativos era enviada a cada três meses para todos os médicos psiquiatras filiados à Associação Brasileira de Psiquiatria. Uma vez recebida uma destas notificações, devidamente preenchida, a possível reação adversa era analisada para verificação da causalidade.

Resultados: Os psiquiatras classificaram como sérias 50 das RAMPs; 150 outras foram consideradas nãosérias. Entre as sérias houve três mortes, 12 relataram risco de vida, 26 RAMPs exigiram ou prolongaram hospitalização e nove notificações descreveram invalidez temporária dos pacientes. Entre os medicamentos, os antidepressivos ficaram em primeiro lugar, com 122 RAMPs notificadas, seguidos dos neurolépticos (46 RAMPs) e anticonvulsivantes (25 RAMPs). Os três principais órgãos e sistemas afetados pelas ARs foram: Sistema Nervoso Central, com 102 ARs, pele e mucosa, com 44, e gastrointestinal, com 21 RAMPs.

Conclusão: Considerando a causalidade, ou seja, a associação entre o medicamento e a RA descrita, em 24 casos, as RAMPs foram considerados Definidas (com "dechallenge" e "rechallenge" positivas; isto é, retirada e reintrodução do medicamento) e 134 outras RAMPs foram classificadas como Prováveis (só "dechallenge" positiva; só com a retirada do medicamento. A "rechallenge" não foi feita).

Descritores Reação adversa a medicamentos. Farmacovigilância. Medicamentos psicoativos. Causalidade de reações adversas às drogas. 


\section{Introduction}

Psychoactive medications represent a sizeable part of the medications used in Brazil. Thus, of 552.6 millions of prescriptions in 2000, 74.9 millions (13.6\%) were for psychoactive medications (National Disease and Therapeutic Index-IMS Health; December 2000-YTD). The prescriptions for these psychoactive medications were filled out, among others, by general practitioners $(29.7 \%)$, followed by psychiatrists (19.3\%), neurologists (9.5\%), cardiologists (5.6\%), and gynecologists/ obstetricians (4.1\%), in that order (National Disease and Therapeutic Index-IMS Health; December 2000-YTD). Among the psychoactive medications sold, benzodiazepines ranked first, followed by antidepressants, but relevant amounts of neuroleptics, antiepileptics and CNS stimulants (mostly amphetamine-like anorectics) were also used.

On the other hand, the psychoactive substances were not devoid of toxicity; there were many reports of adverse reactions (AR) induced by them, including severe ones, involving antidepressants, ${ }^{1-3}$ antiparkinsonian drugs,${ }^{4,5}$ neuroleptics, ${ }^{6,7}$ anticonvulsants ${ }^{8,9}$ and benzodiazepines. ${ }^{10,11}$

Fatal reactions have been also reported for some psychoactive substances. ${ }^{12}$

Needless to say that pharmacovigilance plays a capital role to detect $\mathrm{AR}$ and consequently to protect the user population from such accidents. ${ }^{13-15}$

In Brazil, unfortunately, pharmacovigilance is still in its embrionary phase and there are no governmental reports on the adverse events related to medications in general and, consequently, to psychoactive substances in particular. Those facts led the Department of Psychobiology of the Paulista Medical School at the Federal University of São Paulo to organize a national system to collect, directly from Brazilian psychiatrists, spontaneous data on adverse reactions provoked by psychoactive medications. This activity is known as PSIFAVI (PsicoFarmaco-Vigilância, in Portuguese). This paper describes the results obtained after 30 months of activity, from April 1999 (when the program started) up to September 2001.

\section{Methods}

From April 1999 up to September 2001, the 3,160 Brazilian psychiatrists affiliated to the Brazilian Association of Psychiatry received quarterly a yellow form called 'Notification of a Suspected Psychoactive Medication Adverse Reaction (ARMP)'. Therefore, in the above period of time each psychiatrist received 10 ARPMs; thus, 31,600 ARPMs were sent in that 30-month period. In the same envelope, accompanying each ARMP, it was also mailed a 4-page publication, called PSIFAVI Bulletin, quarterly edited, containing news on adverse reactions produced by psychoactive drugs either in Brazil (very few) or abroad. The total number of Medical Doctors practicing in Brazil is, according to the Federal Council of Medicine (www.portalmedico.org.br), 284,800; therefore, the contacted Brazilian psychiatrists represent $1.1 \%$ of that total.

The following procedure was adopted whenever a duly filledout ARMP was received from a psychiatrist:

- a PSIFAVI letter was sent acknowledging the reception of the ARMP, accompanied by information (scientific literature) on all known adverse reactions produced by the involved psychoactive substance. In order to stimulate the medical doctor to further collaboration he/she was offered, free of charge, a one-year subscription of a Brazilian medical journal (a list of which was enclosed to allow a choice);

- a copy of the ARMP was remitted to the responsible pharmaceutical industry, without the name of the psychiatrist who filled out the notification, requesting more information concerning the ARMP;

- as a next step, the reply of the pharmaceutical industry, when received, was sent to the psychiatrist. In case the pharmaceutical industry requested a direct contact with the doctor, the name and address were only furnished after gave his/ her consent.

Summing up, PSIFAVI adverse reaction notifications were filled out by prescribing psychiatrists. There were, therefore, spontaneous descriptions of adverse reactions made by doctors.

As a final step, each ARMP was studied by two members of the PSIFAVI (one psychopharmacologist medical doctor and a pharmacist) and the occasional relation of causality between the medication and the adverse reaction was assessed, according to the algorithm of Karch and Lasagna. ${ }^{16}$

Whenever further details to clarify the AR were needed, one PSIFAVI member made a phone-call to the notifying doctor. To assess whether the described ARMP was a known reaction to the suspected agent (part of the information necessary to establish causality), the insert package of the medication and information from Micromedex were consulted.

\section{Results}

Two hundred and nineteen ARPMs were received between April 1999 and September 2001. They were posted by 114 psychiatrists working in 13 out of the 26 Brazilian States, what means that several psychiatrists sent more than one ARMP. In those 13 states, $78 \%$ of the 3.160 Brazilian psychiatrists exert their practice. These figures represent that only $3.60 \%$ of the contacted psychiatrists reported adverse reactions suspected of being produced by psychoactive medications. On the other hand, the ARPMs were notified within a 2.5-year period, meaning that, on average, .069 ARPMs were notified per psychiatrist in 2.5 years.

Gender and age of the patients suffering from adverse reactions of the psychoactive medications were as follows: $42.4 \%$ males and $57.6 \%$ females; under 19 years of age, $20.0 \% ; 20$ to 29 years, $23.0 \%$; 30 to 39 years, $27.6 \%$; 40 to 49 years, $10.5 \%$; 50 to 65 years, $8.5 \%$; above 65 years of age $9.7 \%$; non- specified age $.7 \%$.

Of the 219 copies of ARPMs mailed to the pharmaceutical industries, only $104(47.5 \%)$ were answered; these responses were sent to the notifying psychiatrists. On the other hand, the industries requested in 8 occasions the identification of the notifying doctors for further contacts; only one psychiatrist refused contact with the pharmaceutical industry.

Drug adverse reactions were classified into two categories: non-severe and severe. The latter were subclassified into the 
six following categories: requested or prolonged hospitalization; life-threatening; caused temporary or permanent disability; produced congenital anomaly; caused cancer; and death. Table 1 shows the judgment made by psychiatrists about the adverse reactions observed in their patients. We may note that $22.8 \%$ (50), out of 219 reported AR, were considered as severe ones, as described below.

Three deaths (clozapine - 2; levomepromazine - 1). The first death attributed to clozapine was a 55-year-old male schizophrenic patient, who used $300 \mathrm{mg}$ oral daily for 57 days and presented a progressive leucopenia (700 counts); he was a heavy smoker and had also a cancer in pharynx. The second clozapine attributed death was of a 30-year-old man weighing 210 kilograms; he received $600 \mathrm{mg}$ by oral route and later on, in same day, he presented myoclonic convulsion, fell on the floor, followed by cardio-respiratory arrest. The death attributed to levopromazine occurred in a 39-year-old schizophrenic male patient after 26 days of oral administration of $800 \mathrm{mg}$; it was preceded in the previous 15 hours by periods of apnea, abdominal distention and finally a pulmonary edema. During the previous month, the patient was also receiving haloperidol and clonazepam.

Notifying doctors also classified twelve life-threatening reactions: neuroleptic malignant syndrome (haloperidol - 2, olanzapine - 1); suicidal thoughts/attempts (amphepramone 2 , fluoxetine - 1 , venlafaxine - 1); anaphylactic reaction (phenytoin - 1); leucopenia (carbamazepine - 1); myocardial infarct (clozapine 1); glottis edema (fluoxetine - 1); Stevens-Johnson Syndrome (haloperidol - 1).

The 26 AR reported by doctors as requiring or prolonging

Table 1 - Classification of the 219 adverse reactions to psychoactive medications, as described by Brazilian psychiatrists during a $\mathbf{3 0}$ months period (April 1999 - October 2001).

\begin{tabular}{lr}
\hline Adverse Reaction & $\mathrm{N}$ \\
Not classified by the Doctor & 19 \\
Non Severe & 150 \\
Severe & 50 \\
\cline { 2 - 2 } Among the Severe $(\mathrm{n}=50)$ & 219 \\
Resulted in death: & 3 \\
Required/prolonged hospitalization: & 26 \\
Life-threatening: & 12 \\
Persistent/temporary disability & 9 \\
& 50 \\
\hline
\end{tabular}

hospitalization were: neuroleptic malignant syndrome (clozapine - 1, haloperidol - 1); urinary retention (reboxetine 1); renal stones (venlafaxine - 2); dependence syndrome (opium - 1, fenproporex - 1); erythema (venlafaxine - 1); 'marked skin allergy' (lamotrigine - 1); erythema plus fever (phenobarbital 1), urticaria and edema of mucosa (fluoxetine - 1); muscle rigidity, extrapyramidal symptoms and Parkinsonism (fluoxetine - 1; thioridazine - 1, haloperidol - 1); pancreatitis (olanzapine 1); hepatitis (nortriptyline - 1); hepato-renal syndrome (venlafaxine - 1); hypertension and panic attacks(sibutramine - 1); hypertensive crisis (milnacipran - 1; mirtazapine - 1); mania (Hypericum perforatum - 1); tremors and allergic reaction (amitriptyline - 1); agitation and aggressiveness (olanzapine - 1); psychotic crisis (sibutramine - 1); obsessive-compulsive symptoms (risperidone - 1) and Stevens-Johnson Syndrome (carbamazepine - 1).

Finally, there were 9 ARPMs notifying temporary disability, described as follows: hepatitis confirmed by laboratory data (fluoxetine - 1); psychosis (anorectic amphetamine-like substance - 1); muscle rigidity, ataxia and tremors (haloperidol - 1); incapacitating somnolence (sertraline - 1); vomiting, ataxia and paleness (periciazine - 1); parkinsonian syndrome (metoclopramide - 1); intense spasmodic muscle contractions (risperidone - 1); fainting and downfalls (citalopram - 1); and muscle rigidity, fever, constipation and urinary incontinence (periciazine - 1).

Table 2 summarizes all classes of substances psychiatrists attributed to the adverse reactions. Antidepressants ranked first, with fluoxetine ranking first, followed by venlafaxine, sertraline, paroxetine and reboxetine. The other 34 antidepressants not mentioned in Table 2 were mirtazapine, citalopram, clomipramine, tranylcypromine, nortriptyline, bupropion, milnacipran, fluvoxamine, nefazodone, amitriptyline and imipramine.

Risperidone (14 ARPMs) was the most frequently neuroleptic drug cited as cause of adverse reactions, followed by haloperidol, clozapine, thioridazine and olanzapine.

Third, with 25 reports of ARPMs, ranked the antiepileptic medications. Among those, there were 10 reports of reactions caused by phenytoin; however, eight out of the 10 reactions were reported by the same professional describing rash, pruritus and other skin reactions occurring in a same hospital setting, at the same occasion.

Table 2 - Substances responsible for the adverse reactions (total of 219 ARPMs) according to the opinion of the notifying psychiatrists.

\begin{tabular}{|c|c|c|c|c|c|}
\hline \multirow{2}{*}{$\begin{array}{l}\text { Therapeutic } \\
\text { Class }\end{array}$} & \multirow{2}{*}{$\begin{array}{c}\text { Number of } \\
\text { ARPMs }\end{array}$} & \multicolumn{4}{|c|}{ Substances involved } \\
\hline & & Name & $\mathrm{N}$ & Name & $\mathrm{N}$ \\
\hline \multirow[t]{3}{*}{ Antidepressants } & 122 & Fluoxetine & 24 & Paroxetine & 13 \\
\hline & & Venlafaxine & 21 & Reboxetine & 13 \\
\hline & & Sertraline & 17 & Others & 34 \\
\hline \multirow[t]{3}{*}{ Neuroleptics } & 46 & Risperidone & 14 & Thioridazine & 5 \\
\hline & & Haloperidol & 9 & Olanzapine & 4 \\
\hline & & Clozapine & 7 & Others & 7 \\
\hline \multirow[t]{3}{*}{ Antiepileptics } & 25 & Phenytoin & 10 & Lamotrigine & 4 \\
\hline & & Valproic acid & 4 & Oxcarbamazepine & 2 \\
\hline & & Carbamazepine & 4 & Phenobarbital & 1 \\
\hline \multirow[t]{2}{*}{ Anxiolytics } & 8 & Midazolam & 2 & Clonazepam & 4 \\
\hline & & Bromazepam & 1 & Buspirone & 1 \\
\hline \multirow[t]{2}{*}{ Anorectics } & 7 & Diethylpropione & 3 & Sibutramine & 2 \\
\hline & & Fenproporex & 2 & & \\
\hline Others & 11 & & & & \\
\hline
\end{tabular}


The rather surprising small number of 8 ARPMs related to the anxiolytic drugs was followed by seven reactions attributed to the anorectic drugs; two psychotic episodes with suicidal attempts due to chronic use of amphepramone stood out among them. All those seven cases were notified by the psychiatrists as patients referred to them due to the adverse reactions produced by the weight reducing medications prescribed by other medical doctors.

Finally, among the other 11 reported adverse reactions (nonsevere), three were due to zolpidem and four were consequence of phytotherapeutic medications. Among the latter, a Passiflora incarnata suspension in $14 \%$ alcohol vehicle. The patient, a 60 year-old woman with previous history of drug abuse, escalated the dose of this phytomedicine because she felt 'happy and drunk' as if she had actually drunk a 'real alcoholic beverage'.

Table 3 shows which were the target organs involved in the adverse reactions. Psychological and neurological signs/symptoms related to central nervous system were the most frequentlycited adverse reactions. Among the psychological/mental disturbances stood out four cases of suicidal thoughts/attempts (diethylpropione - 2 cases; fluoxetine - 1; venlafaxine - 1), six patients reporting hallucinations (bromazepam - 1; nefazodone - 1 ; fluvoxamine - 1 ; risperidone - 1 ; bupropion - 2 ), one case of dependence (opium preparation) and two abstinence syndromes (fenproporex - 1; paroxetine - 1). Psychiatrists also notified three cases of parkinsonism (haloperidol - 1; olanzapine - 1; thioridazine - 1), five neuroleptic malignant syndrome (haloperidol - 3 cases; clozapine - 1; thioridazine - 1) and one more possible case of neuroleptic syndrome was described by one psychiatrist as a patient with $39^{\circ} \mathrm{C}$, tetanus and autonomic reactions (periciazine).

Skin and mucosal membrane adverse reactions were notified through 44 ARPMs; among them two reactions directly classified by the notifying doctors as Stevens-Johnson Syndrome (imipramine - 1, haloperidol - 1).

Concerning the patients' sexual functioning, anorgasmia, delayed ejaculation, decreased libido and priapism were described by 16 doctors as adverse reactions produced by the psychoactive medications (Table 3 ).

Table 3 - Organs and systems affected by the adverse reactions produced by psychoactive medications.

\begin{tabular}{lcc}
\hline $\begin{array}{l}\text { Target Organ/ System/ } \\
\text { Apparatus }\end{array}$ & \multicolumn{2}{c}{$\begin{array}{c}\text { Adverse Reaction } \\
\text { Number* }\end{array}$} \\
\hline Central Nervous System: & & \\
mental/ psychological & 71 & 30.4 \\
neural/ muscular & 31 & 12.7 \\
Skin and mucosal & 44 & 19.4 \\
Genital & 16 & 7.0 \\
Gastrointestinal & 21 & 9.2 \\
Cardiovascular & 09 & 4.0 \\
Renal & 07 & 3.1 \\
Vision & 12 & 5.3 \\
Hormonal & 08 & 3.5 \\
Fever & 03 & 1.3 \\
Respiratory & 05 & 2.2 \\
Blood & 05 & 2.2 \\
Total & 232 & 100 \\
\hline *Total number is above the 219 ARs reported, due to the fact that some of the adverse
\end{tabular}

${ }^{*}$ Total number is above the 219 ARs reported, due to the fact that some of the adverse reactions affected more than one organ/system.
The causality analysis using the algorithm of Karch and Lasagna ${ }^{16}$ produced the following results. In 23 cases the psychiatrists reintroduced the psychoactive medication (rechallenge), after its previous suspension (dechallenge), with the reappearance of the adverse reaction symptomatology; therefore, for these 23 cases there had been a Definite causality between the medication and the described AR. They were: valproic acid - 1 AR (intense pain in epigastrium); citalopram - 2 ARs (dysuria; erythema and pruritus); desipramine - 1 AR (intense fatigue); fenproporex - $1 \mathrm{AR}$ (dependence and withdrawal symptoms); fluoxetine - 7 ARs (alopecia; alopecia and acne; anorgasmia; stomach upset; tongue protrusion and swallowing difficulty; visual disturbance; metrorrhagia); lamotrigine - 1 AR (skin rash, lymphadenopathy and fatigue); fluvoxamine - $1 \mathrm{AR}$ (derealization, despersonalization and anxiety); reboxetine - 1 AR (irritability); risperidone - 2 ARs (constipation and apathy; acathisia and muscle spasm); sertraline - 5 ARs (diarrhea; stomach upset; urticaria and pruritus, nausea and vomiting) and thioridazine - $1 \mathrm{AR}$ (orgasm without ejaculation).

For another 134 ARs the dechallenge produced an improvement of the symptomatology but the rechallenge was not performed; therefore, in those cases causalities were classified as Probable.

Twenty-five other ARs appeared in the patients after an appropriate time interval between the ingestion of the medication and the occurrence of the event; moreover, they had not been previously described for that drug and the adverse event could not be reasonably explained through the clinical state of the patients or due to other medications. According to Karch and Lasagna (16), for those 25 ARs, the medications-event causalities were classified as Conditional.

Causalities for four other ARs were classified as Possible; and 25 ARs were considered as Not-Related, as they actually describe lack of efficacy of the medication, or patients did not improve after dechallenge. Finally, it was not possible to establish the causality for the last 8 remaining ARPMs.

\section{Discussion}

The present study describes 219 adverse reactions to psychoactive medications notified by 114 Brazilian psychiatrists that correspond to $3.60 \%$ of the total amount of the 3,160 ones affiliated to the Brazilian Association of Psychiatry.

Underreporting is a common feature of pharmacovigilance all over the world with, at most, $10 \%$ of the physicians in several countries having well-developed notifying pharmacovigilance systems; on the other hand, in many other countries, reporting rates are much lower. ${ }^{17}$ Research projects aiming to increase the reporting of suspected drug reactions have been performed. ${ }^{18}$

It may be concluded, therefore, that the amount of AR reports received is fairly acceptable taking into account that pharmacovigilance is by no means developed in Brazil and that ARs were notified only by psychiatrists. It is, however, surprising the low level of cooperation of the pharmaceutical industry; in fact, only $47.5 \%$ of the ARPMs were commented by 
the companies; and only 8 contacts with the notifying doctors were requested.

Another point which may be related to the small number of received ARs is regarding the very low number of adverse reactions from older and widely used psychoactive medications. For example, there were only 1 report of AR for imipramine, 2 for amitriptyline, 5 for thioridazine, 9 for haloperidol, none for chlorpromazine, and 8 for benzodiazepine substances (none for diazepam). These figures contrast with the $24 \mathrm{AR}$ reported for fluoxetine, 21 for venlafaxine, and 14 for risperidone. Brazilian psychiatrists are probably so used to the old psychoactive substances that their attention is concentrated on the new developments of the psychotherapeutic medications. It is as if for Brazilian psychiatrists the reporting of adverse reactions were a new issue and should be concerned mostly to new psychoactive medications.

On the other hand, if the methodology employed in this study were applied to all other Brazilian physicians and hypothesizing that the rate of their reporting would be similar to that of psychiatrists, then nearly 19 thousands AR would be obtained every two-year period. This is not much below the 200 ARs per million inhabitants yearly reported in some countries $;{ }^{17}$ with 170 million inhabitants, Brazil may have the potential to report nearly 34,000 AR annually. Therefore, we believe that the methodology employed in the present study could be useful if applied thoroughly, as it may yield good results when implanting a new system to collect AR in countries like Brazil.

Another issue that deserves further comment refers to the quality of the reported ARs. They were obtained from patients seen in the psychiatrists' own private clinics (or private hospitals) and, therefore, receive careful attention and follow-up. In fact, most of the clinical descriptions of the AR fit reasonably well into the definitions of AR established by CIOMS, ${ }^{19}$ except for the five neuroleptic malignant syndrome cases as in none of them the activity of creatinine phosphokinase was measured, ${ }^{19}$ although all the cases presented hyperthermia, rigidity and disturbed autonomic function.

The fact that only 23 of the 219 ARPMs (10.9\%) were classified as Definite deserves attention. According to Karch \& Lasagna, ${ }^{16}$ such causality is attributed when dechallenge is followed by rechallenge and reappearance of the AR. However, such procedure may not be always acceptable due to safety and ethical reasons, ${ }^{20}$ for example, it would be unacceptable to re-expose the patients to the medications apparently causing the 12 life-threatening adverse reactions described in this study. Furthermore, in some other cases dechallenge is not feasible (as in the 3 death cases) or would not function as, for example, in cases of cataract, drug dependence, myocardial infarct, etc., which would not disappear with dechallenge. Therefore, the low figure of $10.9 \%$ of ARPMs with cause and effect estab- lished as Definite does not mean that the remaining adverse reactions should be taken as certainly not being caused by the medications.

Finally, 25 ARs were classified as Conditional, meaning that they were unknown reactions to the medications. They were: buspirone - 1 (hypotension); thioridazine - 1 (feet edema); tranylcypromine - 1 (polydipsia and polyuria); paroxetine 1 (fever and joint pain); clomipramine - 1 (metrorrhagia); sibutramine - 1 (hypomania); valproic acid 1 (macroglossia and oral angioedema); olanzapine - 1 (leukocytosis); sertraline - 1 (petechia); phenytoin - 1 (encopresis); cloxazolam - 1 (erectile dysfunction); bromazepam - 1 (visual hallucination); fluoxetine - 1 (glottis edema and urticaria); nefazodone - 2 (visual and auditory hallucination; sleep apnea and anxiety); venlafaxine - 2 (spontaneous abortion; obsessive compulsive reaction); milnacipran - 2 (pruritus; hypertension); and reboxetine - 6 (vivid dreams; piloerection; ejaculation delay; hematuria; hypertension; oropharynx edema and pain). Those Conditional ARs do not mean that this study is providing 25 early warnings or signs of previously unknown adverse reactions to the medications. Actually, the description of a new adverse reaction to a drug is a complex process involving several steps and careful scrutiny of the data. ${ }^{21,22}$ Nevertheless, we may note that the Brazilian population differs considerably (ethnicity; weight and height; different nutritional/environmental/social/economical conditions) from those of developed countries in which most of drug dosage schemes and description of adverse drug reactions were produced. If this is true, further studies on the above-described Conditional adverse reactions and other pharmacovigilance issues in developing countries like Brazil should be interesting.

Undoubtedly, any therapeutic process involving administration of medications has the inherent possibility of producing undesirable adverse reactions to the patients. Taking this truism into consideration, the present study raises three points. First, psychiatrists (as well as other medical doctors) should be constantly reminded of that possibility and thus, advised to prescribe with parsimony and in cases of real clinical necessity.

Second, the pharmaceutical industries should be obliged to state clearly in the insert packages and promotional material all the warnings, contra-indications and the occurrence of possible adverse reactions. Lastly, the existence of a Governmental Pharmacovigilance Service is essential, in order to collect and disseminate to all professionals information on the occurrence of adverse reactions and precautions to prevent as well as to treat them.

Needless to say that all these activities demand from psychiatry (as well as from other medical specialties) close and constant collaboration between medical schools, sanitary surveillance of State and Federal Governments and specific Associations or Societies such as the Brazilian Psychiatric Association. 


\section{References}

1. Committee on safety of Medicines. Selective serotonin reuptake inhibitors. Curr Probl Pharmacovigil 2000;26:9-10.

2. Vida S, Looper K. Precision and comparability of adverse events rates of newer antidepressants. J Clin Psychopharmacol 1999;19:416-25.

3. Azaz-Livshits T, Hersko A, Ben-Chetrit E. Paroxetine associated hepatotoxicity: a report of 3 cases and a review of the literature. Pharmacopsychiatry 2002;35:112-5.

4. [WHO] World Health Organization. Pramipexole - sudden onset of sleep. Information Exchange System: Alert no 87 July 1999.

5. Fernandez HH, Friedman JH. Punding on L-Dopa. Mov Disord 1999; 14:836-8.

6. Muscettola G, Barbato G, Pampallona S, Casie M, Bollini P et al. Extrapiramidal syndromes in neuroleptic-treated patients: prevalence, risk factors and association with tardive dyskinesia. J Clin Psychopharmacol 1999;19:203-8

7. Levenson JL. Neuroleptic malignant syndrome after the initiation of olanzapine. J Clin Psychopharmacology 1999;19:177-8.

8. Gram L, Bentsen KD. Hepatic toxicity of antiepileptic drugs: a review. Acta Neurol Scand 1983;68(Suppl 97):81-90.

9. Ferrie CD, Robinson RO, Panayiotopoulos CP. Psychotic and severe behavioral reactions with vigabatrin: a review. Acta Neurol Scand 1996;93:1-8.

10. Lader M, Morton S. Benzodiazepine problems. Br J Addict 1991;86:823-8.

11. Barbone F, McMahon AD, Davey PG, Morris AD, Reid IC, McDevitt DG et al. Association of road-traffic accidents with benzodiazepine use. Lancet 1998;352:1331-6.

12. Glassman AH, Bigger JJT. Antipsychotic drugs: prolonged QTc interval, Torsade de Pointes, and sudden death. Am J Psychiatry 2001;158:1774-82.

13. Faich GA. US Adverse drug reaction surveillance 1984-1994. Pharmacoepidemiol Drug Saf 1996;5:393-8.

14. Garcia-Martin M, Claret PL, Cavanillas AB, Castillo JDL, Garcia ME, Vargas RG. Proportion of hospital deaths associated with adverse events. J Clin Epidemiol 1997;50:1319-26.
15. Classen DC, Pestotnik SL, Evans RC, Lloyd JF, Burke JP. Adverse drug events in hospitalized patients. JAMA 1997;277:301-6.

16. Karch FE, Lasagna L. Toward the operational identification of adverse drug reactions. Clin Pharmacol Ther 1997;21:247-54.

17. Meyboom RHB. Detecting adverse drug reactions. Pharmacovigilance in the Netherlands. The Netherlands Pharmacovigilance Foundation LAREB, Nijmegen; 1998.

18. Scott HD, Renshaw AT, Rosenbaum SE, Waters WJ, Green M, Andrews LG et al. Physician reporting of adverse drug reactions. JAMA 1990;263:1785-8

19. Bankowski Z, Bruppacher R, Crusius I, Gallagher J, Kremer G, Venulet J, editors. Reporting adverse reactions - Definitions of terms and criteria for their use. Council for International Organizations of Medical Sciences (CIOMS). Geneva; 1999.

20. Wan Po A, Kendall MJ. Causality assessment of adverse effects: when is rechallenge ethically acceptable ? Lancet 1999;354:683.

21. Venning GR. Validity of anecdotal reports of suspected adverse drug reactions: the problem of false alarms. BMJ 1982;284:249-52.

22. Meyboom RHB, Egberts ACG, Edwards IR, Hekster VA, De Koning EHP, Gribnau EWJ. Principles of signal detection in pharmacovigilance. In Detecting Adverse Drug Reactions. Pharmacovigilance in the Netherlands. Ed. RHB Meyboom. The Netherlands Pharmacovigilance Foundation LAREB, Nijmegen; 1998.

\section{Correspondence:}

Elisaldo Luiz de Araújo Carlini

Depto. de Psicobiologia - Unifesp

Rua Botucatu, $8621^{\circ}$ andar

04023-062 São Paulo, SP, Brazil

E-mail: carlini@psicobio.epm.br 